\title{
Climate sensitivity uncertainty and the necessity to transform global energy supply
}

\author{
Bob van der Zwaan ${ }^{\mathrm{a}, \mathrm{b}, *}$, Reyer Gerlagh ${ }^{\mathrm{c}}$ \\ ${ }^{\text {a }}$ Energy research Centre of the Netherlands (ECN), Policies Studies Department, \\ P.O. Box 37154, 1030 AD Amsterdam, The Netherlands \\ ${ }^{\mathrm{b}}$ Harvard University, John F. Kennedy School of Government, 79 J.F.K. Street, Cambridge, MA 02138, USA \\ ${ }^{\mathrm{c}}$ Vrije Universiteit Amsterdam, Institute for Environmental Studies (IVM), De Boelelaan 1087, 1081 HV Amsterdam, The Netherlands
}

Received 15 July 2005

\begin{abstract}
This paper analyses the policy relevance of the dominant uncertainty in our current scientific understanding of the terrestrial climate system, and provides further evidence for the need to radically transform - this century - our global energy supply infrastructure, given the global average temperature increase as a result of anthropogenic carbon dioxide $\left(\mathrm{CO}_{2}\right)$ emissions. We investigate the effect on required $\mathrm{CO}_{2}$ emission reduction efforts, both in terms of how much and when, of our present uncertain knowledge of the climate sensitivity to a doubling of the atmospheric $\mathrm{CO}_{2}$ concentration. We use a top-down integrated assessment model in which there are two competing energy sources, fossil and non-fossil. Technological change is represented endogenously through learning curves, and modest but non-zero demand exists for the relatively expensive carbon-free energy resource. We find that during the forthcoming two decades the relative roles of carbon-free energy and energy savings are similar, while in the long run the importance of carbon-free energy deployment becomes predominant, independent of the assumed climate sensitivity, but dependent on some of our model's characteristic features. We also find that, in the absence of the realisation of drastic energy efficiencies or a massive deployment of carbon capture and storage technologies, non-carbon energy resources should provide $10-30 \%$ and $80-90 \%$ of total energy supply, in 2020 and 2100 , respectively. Finally, we observe that in our model the timing of the emissions reduction effort is nearly linear and close to independent of either the climate sensitivity or policy target.
\end{abstract}

(C) 2005 Elsevier Ltd. All rights reserved.

Keywords: Global warming; $\mathrm{CO}_{2}$ emissions; Climate sensitivity; Fossil to non-fossil transition; Carbon-free power; Energy savings

\section{Introduction}

The sensitivity of the global mean temperature to increasing levels of atmospheric carbon dioxide $\left(\mathrm{CO}_{2}\right)$ is currently known only to about a factor of three. To be more precise, the climate sensitivity, $\Delta T_{2 X}-$ defined as the global mean climatological temperature change $\Delta T$ resulting from a doubling of atmospheric $\mathrm{CO}_{2}$

\footnotetext{
*Corresponding author. Energy research Centre of the Netherlands (ECN), Policies Studies Department, P.O. Box 37154,1030 AD Amsterdam, The Netherlands. Tel.: + 31224564442.

E-mail address: vanderzwaan@ecn.nl (B. van der Zwaan).
} 
content $X$-is thought, today, to lie in a range of about $1.5-4.5^{\circ} \mathrm{C} .{ }^{1}$ These numbers have been derived primarily from computer-models, have been reported by the International Panel on Climate Change (IPCC), and have subsequently been used by both scientific and policy-making communities the world over for almost a decade now [1,2]. In a recent article, Caldeira et al. [3] reported their finding that, in analyses in which scientists attempt to determine the levels of allowable $\mathrm{CO}_{2}$ emissions, the uncertainty with which we currently know the value of the climate sensitivity, $\Delta T_{2 X}$, has a larger effect (that is, is more determinant for the calculation of these levels) than the uncertainty in our understanding today of the carbon cycle. Also, previous studies emphasized the significance of climate sensitivity uncertainties in optimal control models designed to rationalise short- and long-term climate change policy (see, e.g., the work by Lempert et al. [4] and Ambrosi et al. [5]). While the sensitivity parameter represents undoubtedly one of the largest sources of uncertainty in studies of global warming, other parameters (including those concerning climate thresholds, the carbon cycle, as well as the damages of climate change and the costs of reducing greenhouse gases) are also important in this matter and should as such be considered (as demonstrated, for example, by Nordhaus and Popp [6] and Keller et al. [7]). Because of the sizeable uncertainties that dominate so many of the scientific results in the field of climatic change studies, and the relevance of these uncertainties for effective and efficient global warming policy-making, the subject of uncertainty analysis has recently been receiving increased attention (as can e.g. be seen from the number of conferences today dedicated to this topic; see, for example, [8]). This article explores the relation between climate sensitivity uncertainties and the necessity to transform world energy supply. In particular, we put our modelling results into perspective with the findings presented by Caldeira et al. [3] and focus on the desired transition of the global energy system during the 21 st century.

Today's global energy supply is highly dependent on fossil fuels. The choice for new, renewable or other sources (or a combination of these) as the basis of our energy system will undoubtedly require a costly transition. Nonetheless, for the long run, such a transition seems inevitable, given the risks to humankind involved with climate change. Only two main options exist to reduce $\mathrm{CO}_{2}$ emissions. These are energy savings, on the one hand, and a transition to the use of non-carbon energy, on the other hand. ${ }^{2}$ Energy savings are essential for reaching emission reduction targets, especially in the short term, but since energy is essential for economic production (see, for example, [9]), it needs to be complemented by a transformation of the global energy production system. In fact, since the emission intensity of energy production will finally need to fall down to close-to-zero levels [10], a radical energy system overhaul seems imperative. Most scientists and climate specialists today see both an enhanced development of energy-saving technologies and a shift towards non-greenhouse-gas-emitting energy resources as major elements of policies aiming at a stabilisation of atmospheric $\mathrm{CO}_{2}$ concentrations. Until recently, however, most of the top-down integrated assessment models of global warming focused more generally on climate change mitigation, and often on the energy saving option as one of the main routes to reach emission reductions, rather than on a significant technological overhaul to do so. Well-known examples of these are CETA, DICE, MERGE, RICE and FUND [11-15]. Since both [3] and our research allow for major changes in the way mankind converts energy, from carbon to non-carbon based, it is more meaningful to restrict ourselves to a comparison of our results with those of [3], rather than with those of several of the other known top-down models that put less emphasis on fundamental (induced) technical change.

To address the effect of climate sensitivity uncertainties on policies regarding the control and reduction of carbon emissions, as well as on the required timing of these reductions, we use an integrated assessment model that was specially developed to study policy questions related to global warming, energy supply and technological change. The model, DEMETER, is a general equilibrium model that incorporates a simplified climate change module. DEMETER allows analysing energy savings and energy supply transition processes simultaneously, while it does not display the technological detail of many energy systems-engineering models. Not considering it necessary to describe the model in full detail here again (see [16] for an extensive description), we highlight four of its main elements. First, it includes two competing energy technologies, one

\footnotetext{
${ }^{1}$ Note that recent empirical studies indicate that there is significant likelihood that $\Delta T_{2 X}$ lies above this canonical range. This issue is elaborated below.

${ }^{2}$ In this paper we do not consider a third alternative, that is, continuing the use of fossil fuels but decarbonising them through the application of carbon capture and storage technologies.
} 
of which has zero net $\mathrm{CO}_{2}$ emissions. This allows emission reductions to be achievable through a transition towards a carbon-free technology, as an alternative to the substitution of energy by capital and labour. Second, it distinguishes old from new capital, in such a way that substitution possibilities between production factors only apply to new stocks of capital. This so-called 'vintage' approach allows for using different substitution elasticities for the short and long term, and can, in particular, describe a slow diffusion process. Third, it includes learning-by-doing, through the use of learning curves. In this way, a transition towards alternative technologies leads to lower energy production costs for these technologies, and thereby enhances their opportunities and accelerates the transition process (see also [17]). Fourth, it includes substitution elasticities, such that new technologies can spread before they become fully mature - even though their production costs are initially high.

DEMETER has been used successfully already for a few different research subjects (see $[16,18-20]) .{ }^{3}$ In this paper, we use DEMETER to investigate the variability of carbon emission reduction efforts, as well as that of their timing, as resulting from uncertainties in climate sensitivity, under the presence of a stringent climate change policy - that is, when constraining the global average temperature increase or applying a stringent constraint to the atmospheric $\mathrm{CO}_{2}$ concentration. We also describe the sensitivity of energy savings and the evolution of the share of non-fossil technologies, to changes in a few of the most relevant model parameters. Below, Section 2 concisely describes the main features of DEMETER and its calibration. Section 3 summarises the recent literature on the climate sensitivity value determination and justifies our choice for the variation range of this parameter. Section 4 presents the results of our analysis, derives the policy implications of current uncertainties in climate sensitivity, and underlines the necessity to transform our global energy supply system. Section 5 summarises our findings and concludes.

\section{Model description and calibration}

DEMETER is an optimal-growth (welfare maximisation) model of the world economy. It is designed to calculate cost-effective carbon taxes that maximise the discounted value of utility obtained from the consumption of a generic consumer good. Welfare is maximised subject to a number of economic, technological and climatic constraints. The model describes three production sectors, one for the consumer good, and two for energy production. The two energy sectors use different technologies: the first 'old' technology uses fossil-fuels $(F)$, while the second 'new' technology uses backstop energy sources (e.g. solar or wind energy) with assumed zero $\mathrm{CO}_{2}$ emissions $(N) .{ }^{4}$ DEMETER uses a vintage approach to describe production processes, allowing a differentiation in short-term and long-term elasticities of substitution between various inputs. The production of the consumer good is described by a nested constant-elasticity-ofsubstitution (CES) function (see [16] for a description). One of our specific assumptions is that production costs decrease endogenously as experience increases (see, for example, [21-23]), and that production costs converge to a strictly positive floor price. We assume a constant learning rate (LR), LR $>0$, for technologies at the beginning of their learning curve, that is, during the first several doublings of cumulative installed capacity. This means that, initially, production costs decrease by a factor ( $1-\mathrm{LR})$, for every doubling of installed vintages. ${ }^{5}$

\footnotetext{
${ }^{3}$ Note that for this analysis the model version DEMETER-1 was used. See the articles mentioned for an extensive description of the equations and optimisation used in DEMETER-1.

${ }^{4} \mathrm{An}$ alternative to equating the carbon-free backstop technology $N$ with non-fossil energy would be to assume that $N$ represents fossil fuels complemented by carbon capture and storage (CCS), which is currently seriously considered as climate change mitigation option. While CCS has not been researched for this paper, it will probably be included in our future research endeavours.

${ }^{5}$ Note that implementing learning-by-doing introduces in principle multi-modalities in the model's objective function, and that, consequently, modelling results may be affected by the choice of the solution algorithm. In our case, however, the solution algorithm choice does not affect our findings, as in this version of DEMETER we do not encounter multiple local optima. While learning-by-doing introduces usually one or more non-convexities, the non-convexity in our simulation is too weak to generate more than one (global) optimum. As in most energy system models for economic climate change analysis multiple local optima are found, especially when learning is present, it is often optimal to specialise in one specific technology. In DEMETER there is only one generic non-carbon technology, which remains more expensive than the fossil-based form of energy, irrespective of the learning in the non-carbon sector. Hence, the model cannot 'lock in' in a local optimum.
} 
Another distinguishing feature of DEMETER is that a long-term elasticity of substitution is modelled between the two energy sources, $F$ and $N$, denoted by $\sigma .^{6}$ The CES aggregation of $F$ and $N$ marks an important extension of our model compared to existing models. It describes a strictly positive demand for the new technology $N$, even if the price of the new technology largely exceeds the price of the old technology $F$. Photo-voltaic energy would be an example, since it is used in remote areas irrespective of its high costs, given the local difficulty to connect to a nearby electricity grid. We have chosen a value for the elasticity of substitution $\sigma$ that is bounded and larger than one. For an extensive justification of this value we refer to [19]. Approximately, the parameter $\sigma$ determines the share of the $F$-based energy source relative to the share of the non- $F$ energy source, $\left(F_{t} / N_{t}\right)$, given their relative production costs, $\left(p_{t}^{F} / p_{t}^{N}\right)$, as follows (as a function of time):

$$
\left(F_{t} / N_{t}\right)=\left(p_{t}^{F} / p_{t}^{N}\right)^{-\sigma} \text {. }
$$

Various analyses have shown that the representation of prevailing physical and economic inertia constitutes a crucial determinant of the policy conclusions that one can derive from economic climate models (see, for example, [24]). In DEMETER such inertia are modelled through the simulation of a combination of energy system features, the most important of which are (1) the vintages structure of the two energy inputs, (2) the CES sum of these energy resources, and (3) the energy cost reductions that occur through learning curves. These characteristics of energy supply have been described in previous articles that report our findings with DEMETER. Interestingly, the combination of these features results in realistic technology expansion rates, as will be demonstrated.

Carbon emissions, $E_{t}$, are proportional to the use of $F$-based energy $F_{t}$, via the aggregate carbon emission factor $\varepsilon_{t}$ :

$$
\varepsilon_{t}=\mathrm{e} t F_{t}
$$

The factor $\varepsilon_{t}$ is assumed to be time-dependent (but exogenous), to account for the de-carbonisation process to which the use of fossil fuels has been subject since the early times of industrialisation, by a transition-in chronological order - from wood to coal, from coal combustion to that of oil, and most recently from coal and oil to natural gas. We suppose that this gradual shift in the mix of (fossil) energy resources towards lower carbon values continues to materialise (hence the applicability of $\varepsilon_{t}$ for the rest of the 21 st century), while in addition an endogenous conversion from $F$ to $N$ may involve a more rapid decarbonisation of the energy system, e.g. through the use of hydrogen as energy carrier and/or the deployment of renewables such as wind or solar energy. ${ }^{7}$ Carbon emissions are linked to the atmospheric $\mathrm{CO}_{2}$ concentration, which in turn determines the global average surface temperature, through a 1-box representation as in the early DICE model [11]. As in [3], the stabilisation level of the atmospheric $\mathrm{CO}_{2}$ concentration, $P_{s t a b}$, and the stabilisation value of the temperature increase, $\Delta T_{\text {stab }}$, are related through:

$$
\frac{P_{s t a b}}{P_{280}}=2^{\left(\Delta T_{\text {stab }} / \Delta T_{2 X}\right)}
$$

in which $P_{280}$ stands for the pre-industrial atmospheric $\mathrm{CO}_{2}$ concentration of $280 \mathrm{ppmv}$, and $\Delta T_{2 X}$, as above, for the climate sensitivity. The central value of $\Delta T_{2 X}$ in this study is assumed to be $3{ }^{\circ} \mathrm{C}$ per doubling of the atmospheric $\mathrm{CO}_{2}$ concentration, but values above the range of $1.5-4.5^{\circ} \mathrm{C}$ have explicitly been inspected as well in our analysis.

The inclusion of a temperature or atmospheric carbon concentration constraint in the model results in a positive shadow price for carbon emissions. This emissions shadow price can be interpreted as the tax required on carbon emissions to meet the temperature or concentration constraint that we impose in our model. Additional to the carbon tax, the model calculates an efficient subsidy on investments in new/renewable energy production. Since investments in non- $F$ energy production lower future costs of energy production, through the learning mechanism, the shadow price (or social costs) for such investments lies below the immediate costs,

\footnotetext{
${ }^{6}$ The CES simulation of total energy supply takes the form $\left(F^{\chi}+N^{\chi}\right)^{1 / \chi}$ with the elasticity of substitution parameter $\chi$ related to the elasticity of substitution $\sigma$ through the relation $\sigma=1(1-\chi)$.

${ }^{7}$ See our former DEMETER publications for a more extensive description of the processes that drive both the exogenous and endogenous decarbonisation technological change.
} 
that is, below the consumption foregone. The gap between this investment shadow price and the immediate costs can be interpreted as the subsidy on investments that internalises the learning effect.

For this paper's purpose, we have basically analysed two kinds of scenarios. The first kind of scenario, 'business-as-usual' (BAU), assumes no control on $\mathrm{CO}_{2}$ emissions. It also assumes that there is no policy stimulating the use of the non- $F$ energy source, that is, it abstracts from both taxes and subsidies. The second kind of scenario sets a ceiling on the average global temperature increase, or, roughly equivalently, a constraint on the atmospheric $\mathrm{CO}_{2}$ concentration. In this study, the average temperature increase is not allowed to rise above $2{ }^{\circ} \mathrm{C}$, compared to its pre-industrial value. This is an ambitious scenario that involves taking drastic emission reduction steps (see [25]). In contrast to the first type of scenario, in the temperatureconstrained scenario it is assumed that both taxes on carbon emissions are applied, and subsidies are available for investments in the non- $F$ energy source.

DEMETER has been calibrated in order to obtain modelling results that mimic real-world phenomena as closely as possible. The world population is assumed to grow from 5.89 billion in 1997 at a rate of $1.45 \%$ per year, levelling off and reaching 11.4 billion by 2100 [26,27]. Gross World Product (GWP) in 1997 is assumed to have been 25.1 trillion US\$1990 [27] and its future annual per capita growth rate is assumed to be $1.5 \%$. The value assumed for the autonomous energy services efficiency improvement (AESEI) is $1.0 \%$ per year. The AESEI measures the productivity increase of our CES aggregate. The combined assumptions on population growth, GWP growth and the value of AESEI result in an energy consumption growth rate of $1.9 \%$ per year in 2000 , which decreases to $0.6 \%$ per year in 2100 .

The aggregation of final energy supply over various energy sources such as electricity and heat is facilitated by conversion of all final energy data in primary energy equivalents. Specifically, for electricity, energy flows measured in ExaJoule per year (EJ/yr) are divided by 0.33 , the typical conversion efficiency from heat to electricity, while electricity prices, measured in US dollars per GigaJoule (\$/GJ), are multiplied by 0.33 , to arrive at volumes and prices, respectively, in primary energy equivalents. Over the year 1997, commercial final energy supply (in primary energy equivalents) based on $F$ energy sources is estimated to have been some $307 \mathrm{EJ}$, and related carbon emissions are assumed to have been $6.3 \mathrm{GtC}$. Carbon emissions related to land-use changes and industrial processes are around $1.3 \mathrm{GtC} / \mathrm{yr}$, and are assumed constant over time. ${ }^{8}$ By dividing the $F$ carbon emissions of $6.3 \mathrm{GtC}$ by the $F$ commercial final energy (services) supply of $307 \mathrm{EJ}$, one obtains the carbon emission intensity of $F$ commercial final energy (services) supply, $\varepsilon_{t}$, which amounts to $0.021 \mathrm{gC} / \mathrm{kJ}$ in 1997. The $F$ technology is assumed to be subject to a 'decarbonisation' of $0.2 \%$ per year, which continues until a floor is reached of $0.016 \mathrm{gC} / \mathrm{kJ}$.

On the basis of the database developed for the IIASA-WEC study [26], final commercial energy consumption in 1997 is estimated to be (in primary energy equivalents) 320 EJ. ${ }^{9}$ From the same database, the share of $F$ technologies in energy production (in 1997) is estimated to be $96 \%$. This corresponds to the $307 \mathrm{EJ}$ mentioned above. The remaining share of $13 \mathrm{EJ}$ is non- $F$ energy. Thus, in Eq. (1), the ratio at the left-handside is about 24. Prices, in primary energy equivalents, for energy derived from natural gas technologies vary in a range from 2 to $3 \$(1990) / G J([29]$, p.41). Since coal, oil and natural gas are more or less competitive, a good reference price in our calculations for the average $F$ energy resource is $2.5 \$ / G J$, in the model start-off year 1997 (this price in primary energy equivalents corresponds to a price of $2.5 \times 3.33=8.3 \$ / \mathrm{GJ}$ in final electricity units). A large spread exists in production costs for energy from e.g. wind and solar energy (electricity) options. Prices, in primary energy equivalents, for commercial final electricity from wind turbines varied in 1995 between 2 and $7 \$(1990) / G J$, in the lowest-cost and highest-cost production cases, respectively [30, p. 54; 19]. Electricity production costs for photo-voltaic systems are still significantly higher than those for wind energy [30, p. 21]. We consider a realistic range for the ratio of production costs (non-fossil vs. fossil) to be a factor varying from 2 to 5, consistent with an elasticity of substitution ranging from about $\sigma=2-4$. As central value, we take $\sigma=3$. Given $F$ energy prices of $2.5 \$ / G J$, this value for $\sigma$ is consistent—see Eq. (1)—with

\footnotetext{
${ }^{8}$ Note that this value is well within the range of $0.8-2.4 \mathrm{GtC} / \mathrm{yr}$ as proposed by [28]. We have chosen a figure slightly smaller than the central value of $1.6 \mathrm{GtC} / \mathrm{yr}$ to account for the improvements in carbon emission reductions that are expected in this sector over the 21 st century.

${ }^{9}$ This excludes non-commercial biomass use, as well as 'traditional' carbon-free sources such as nuclear energy and hydropower. However important these may be, we assume that in this analysis the non-carbon energy resource $N$ does not include these energy resources, for ease of exposition.
} 
production costs for the non- $F$ energy source of $7.2 \$ / G J$, in the year 1997 (this latter price in primary energy equivalents corresponds to a price of $7.2 \times 3.33=24 \$ / \mathrm{GJ}$ in final electricity units). For the basis parameter values, in 1997, energy production accounts for about 2.7\% of GWP. As lower bound for $\sigma$ we take $\sigma=2$, and we adjust the initial production costs for the non- $F$ energy source accordingly, to $12.2 \$ / \mathrm{GJ}$. As upper bound we take $\sigma=2$, and we adjust initial non- $F$ prices to $5.5 \$ / \mathrm{GJ}$.

The learning rate for non- $F$ energy resources is assumed to be $20 \%$ per doubling of installed vintages, in line with the empirical evidence on this variable for e.g. solar power and wind suggesting that the learning rate ranges from $8 \%$ to $35 \%$ [31]. The $F$ energy technology is assumed to have used most of its learning potential already: whereas a learning rate similar to that of non-fossil energy is assumed, future expected energy supply does not allow many doublings of the present extensive fossil fuel use, so that the realisable learning cost reductions - according to the theory of learning-by-doing - are assumed to be modest. The cumulative capacity of installed vintages up to the year 1997 is estimated to be about 1200 and 32 EJ for the $F$ energy option and the non- $F$ energy alternative, respectively. ${ }^{10}$ Under the baseline scenario, the cumulative capacity of installed vintages for the carbon-free energy technology is doubled by 2020. Consequently, under the central parameter choice, production costs have decreased by $20 \%$, and for $\sigma=3$ the market share will have increased by approximately $75 \%$, corresponding to an increase of $3 \%$ in total energy supply, from $4 \%$ to $7 \%$.

\section{Climate sensitivity uncertainty}

When in 1979 a committee was convened for the US National Academy of Sciences to prepare a report on the effects of increased levels of $\mathrm{CO}_{2}$ on our climate, a first climate change sensitivity range was born. The two American models that were used for the study obtained 2 and $4{ }^{\circ} \mathrm{C}$, respectively, for the value of the climate sensitivity parameter. Since $0.5^{\circ} \mathrm{C}$ was assumed a reasonable margin of error, the climate sensitivity was thought to likely lie in the range of $1.5-4.5^{\circ} \mathrm{C}$. Subsequently, this range was adopted in basically every global warming assessment that has appeared since then, including the first two assessment reports of the IPCC. Even while the number of climate change models increased and as they were gradually extended and refined, the climate sensitivity spread remained basically unchanged. Again, the last (third) IPCC Assessment Report to date conventionally quotes a climate sensitivity range of $1.5-4.5^{\circ} \mathrm{C}$, with $2.5^{\circ} \mathrm{C}$ as 'best guess' [2]. At a recent international workshop, ${ }^{11}$ most participating scientists agreed on a most probable climate sensitivity of around $3{ }^{\circ} \mathrm{C}$ plus or minus a half-degree or so [32]. Three complementary approaches were examined: (1) simulations by a collection of expert-designed independent climate models, (2) simulations by a single climate model with thorough variations of some of its parameters, and (3) paleoclimatic studies over a range of time scales. As all three of these approaches point to sensitivities in the same vicinity, 'the middle of the canonical range is looking like a good bet' [32]. Given the consistent use of the range of $1.5-4.5^{\circ} \mathrm{C}$ by the IPCC in their three assessment reports, and the recent confirmation of $3{ }^{\circ} \mathrm{C}$ as a 'good-bet' central value in the preparation of IPCC's Fourth Assessment Report, we have in our main analysis opted for the values 2, 3 and 4 as, respectively, low, central and high realisations of the climate sensitivity.

There is an increasing number of authors, however, who point out that the climate sensitivity may well exceed this range at the higher end. Through a Bayesian statistical analysis of the advanced greenhouse effect, Tol and de Vos [33] demonstrate that observational data exclude the climate sensitivity to be small, but cannot exclude it to be large; the mode of the climate sensitivity probability density function is estimated to be $3.8^{\circ} \mathrm{C}$, which is higher than the best guess of the IPCC. Andronova and Schlesinger [34], using a simple climate-ocean model and observed near-surface temperature records, find that as a result of natural variability and uncertainty in the climatic radiative forcing, the $90 \%$ confidence interval for $\Delta T_{2 X}$ is $1.0-9.3^{\circ} \mathrm{C}$, implying that there is a likelihood of $54 \%$ that $\Delta T_{2 X}$ lies outside the IPCC range. With the use of recent climate observations, Forest et al. [35] derive joint probability density distributions for three key properties of the climate system, involving a $5 \%-95 \%$ confidence interval from 1.4 to $7.7^{\circ} \mathrm{C}$ for the climate sensitivity parameter. A climate sensitivity estimate by Gregory et al. [36] —on the basis of the increase in ocean heat content observed in recent decades, the surface temperature changes measured since 1860, and analyses of the

\footnotetext{
${ }^{10}$ For how we derived these figures for the cumulative installed capacity of past vintages, we refer to [19].

${ }^{11}$ Workshop on Climate Sensitivity of the Intergovernmental Panel on Climate Change, Working Group I (Paris, 26-29 July 2004).
} 
radiative forcing of the climate system - obtains a probability density function for values of the effective climate sensitivity, with a lower bound of $1.6{ }^{\circ} \mathrm{C}$ (5th percentile), a median of $6.1^{\circ} \mathrm{C}$ and a mode of $2.1^{\circ} \mathrm{C}$. Knutti et al. [37] present a neural network-based climate model substitute that increases the efficiency of large climate model ensembles by at least an order of magnitude, and find that the surface warming exceeds the range projected by [2] for almost half of the ensemble members, the main reason being that the climate sensitivity is only poorly constrained by observational data.

The 'three degrees consensus' paper by Kerr [32] mentioned only three prevailing methods of estimating the climate sensitivity $\Delta T_{2 X}$. Recent empirical estimates of $\Delta T_{2 X}$ based on instrumental temperature observations, similar to the ones reported in the 5 references above, were not included. On the basis of such empirical analyses, one could conclude that the claim 'the middle of the canonical range is looking like a good bet' is unwarranted; the mentioned empirical studies have lead to an increase in the uncertainty of $\Delta T_{2 X} \cdot{ }^{12,13}$ Still, while recognising the relevance of these recent findings, we think that for the time being, and until the publication of the next IPCC assessment, it is best to stick with the common consensus and currently most quoted literature - however conservative it may be - in the core of our analysis. Our main finding (that there is great need for fundamentally transforming global energy supply) does not change under values of the climate sensitivity that are higher than the canonical range of $1.5-4.5^{\circ} \mathrm{C}$ - as a matter of fact, it can only become stronger as a result. If our conclusion holds for values in this range, it will certainly hold for higher values.

Nevertheless, in order to reflect the importance and concern we attach to the above-mentioned recent empirical estimates of $\Delta T_{2 X}$, we have also investigated the behaviour of our model under climate sensitivity values higher than $4.5^{\circ} \mathrm{C}$. In particular, we have performed an analysis with climate sensitivity values of 5 and $6^{\circ} \mathrm{C}$, and report below our findings under the assumption of these values, along with our main results under the more conservative climate sensitivity values of 2 and $4{ }^{\circ} \mathrm{C}$ with $3{ }^{\circ} \mathrm{C}$ as 'good-bet' central value. At any rate, the last word has not been said on the subject of climate sensitivity, the 'climate change commitment' mankind has already incurred, and the global warming we are still likely to experience this century $[38,39]$.

\section{Results}

Using the model and parameter values as described above, and with the stringent temperature constraint of $2{ }^{\circ} \mathrm{C}$, we have calculated the 'optimal' carbon emission path under three different climate sensitivities. Fig. 1(A) shows the $\mathrm{CO}_{2}$ emission evolutions both under a BAU scenario (in solid squares) and under five different scenarios in which global warming is controlled through some policy intervention-in modelling terms through the imposition of an exogenous constraint on our simulations. Among the five climateconstrained scenarios, the first three cases involve a limitation of the average global temperature increase to $2{ }^{\circ} \mathrm{C}$, each under a different climate sensitivity assumption.

The central climate sensitivity we use is a $3{ }^{\circ} \mathrm{C}$ temperature increase resulting from a doubling of the atmospheric concentration of $\mathrm{CO}_{2}(\mathrm{C} /$ doubling $)$. We have varied this climate sensitivity from $3{ }^{\circ} \mathrm{C} /$ doubling down to $2{ }^{\circ} \mathrm{C}$ /doubling and up to $4{ }^{\circ} \mathrm{C}$ /doubling. A $4{ }^{\circ} \mathrm{C}$ /doubling climate sensitivity involves, naturally, a more stringent climate policy than the case in which we use a $3{ }^{\circ} \mathrm{C} /$ doubling, so that more radical emission reductions are called for in the former case, compared to those needed in the latter. A $2{ }^{\circ} \mathrm{C} /$ doubling climate sensitivity clearly involves less stringent policy measures, as demonstrated in Fig. 1(A). For the reasons give above, we have only considered these three states of nature in the core of our analysis (and have not assigned probabilities to them), to deal with the issue of uncertainty, in order to provide some general bounds for policy

\footnotetext{
${ }^{12}$ In a-to our knowledge at least-unpublished letter, one of the anonymous reviewers has correctly pointed out, through a figure summarizing the results of these 5 empirical studies in terms of box plots for the 5 th, 50 th and 95 th percentile values of their cumulative distribution functions for $\Delta T_{2 X}$, that there is disagreement about the median of $\Delta T_{2 X}$, from 2.2 to $5.0^{\circ} \mathrm{C}$, and the 95 th percentile, from 7.5 to $10.0{ }^{\circ} \mathrm{C}$. These empirical studies indicate that there is more than a $50 \%$ likelihood that $\Delta T_{2 X}$ lies outside the canonical range of $1.5-4.5^{\circ} \mathrm{C}$, with disquietingly large values not being precluded.

${ }^{13}$ As the same referee confirms what others have argued before (see, e.g., [41]), uncertainty is not a reason for doing nothing. The large uncertainty in $\Delta T_{2 X}$ is the reason to adopt a near-term hedging strategy of purchasing insurance against an unknown climate future [24,42]. For $\Delta T_{2 X}$ to be as high as the empirical studies allow, there must be negative net aerosol forcing, and solar irradiance before 1978 must not have varied by much more than observed by satellites since $1978[34,43,44]$. In order to reduce the uncertainty in $\Delta T_{2 X}$ it is essential to reduce the uncertainty in radiative forcing, however challenging this may be.
} 

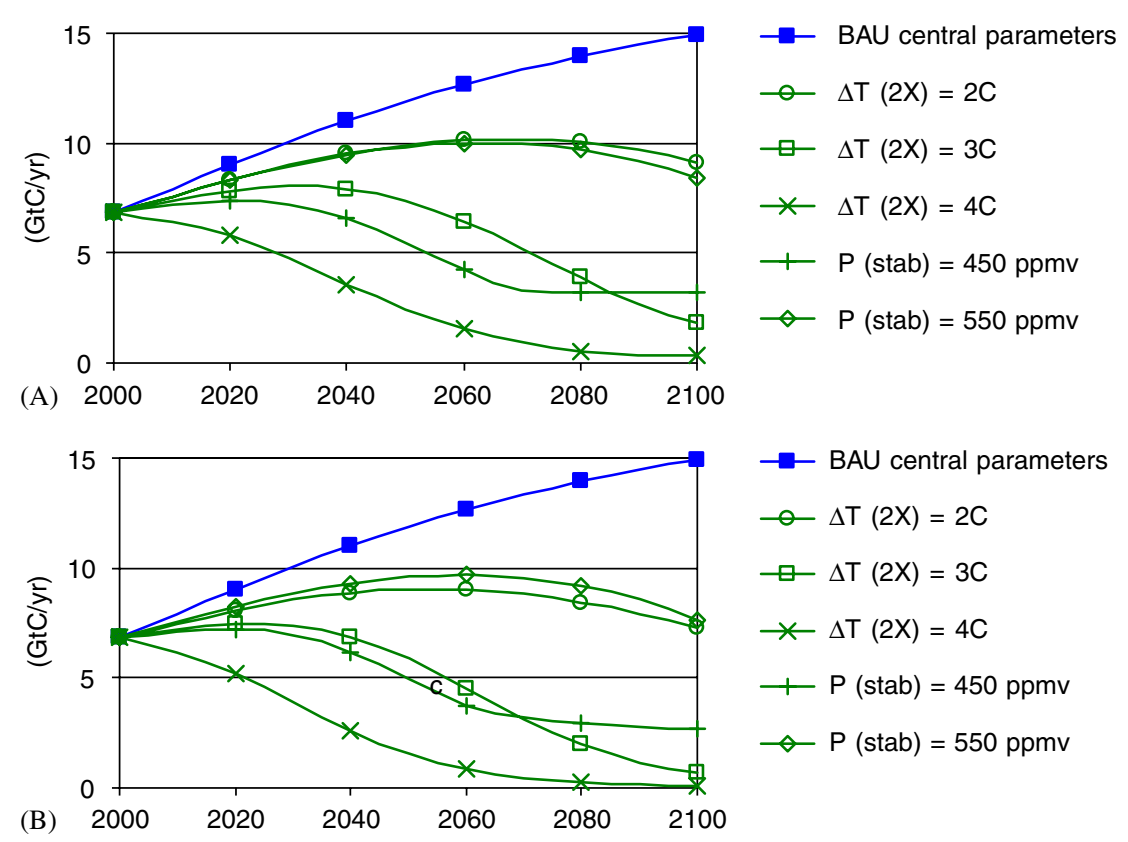

Fig. 1. (A) $\mathrm{CO}_{2}$ emissions for a business-as-usual (BAU) scenario, and under various climate sensitivities $\Delta T_{2 X}$ (with values of respectively 2,3 , and $4{ }^{\circ} \mathrm{C}$ ) and policy scenarios (while the three scenarios with different values for $\Delta T_{2 X}$ involve a climate constraint of $2{ }^{\circ} \mathrm{C}$, the other two scenarios have $\mathrm{CO}_{2}$ concentration stabilisation constraints of 450 and $550 \mathrm{ppmv}$, respectively). Climate change is modelled through a 1-box representation. (B) $\mathrm{CO}_{2}$ emissions for a BAU scenario, and under various climate sensitivities $\Delta T_{2 X}$ (with values of respectively 2,3 , and $4{ }^{\circ} \mathrm{C}$ ) and policy scenarios (while the three scenarios with different values for $\Delta T_{2 X}$ involve a climate constraint of $2{ }^{\circ} \mathrm{C}$, the other two scenarios have $\mathrm{CO}_{2}$ concentration stabilisation constraints of 450 and $550 \mathrm{ppmv}$, respectively). Climate change is modelled through a 3 layer representation.

actions. We have not performed a more extensive stochastic analysis, with e.g. probability measures attached to different states of nature (as discussed in [40]), nor have we applied a Monte Carlo simulation, expected value optimisation, or dynamic stochastic optimisation to account for the improvement in time of our common knowledge regarding climate change, in our investigation of the effect of uncertainty on climate policies. These we consider beyond the more limited and focused scope of this article, as the central thrust of our results can be demonstrated through a sensitivity analysis with the three mentioned values of the climate sensitivity parameter, for which none of the mentioned fancier techniques are needed (however desirable these alternative methods may be for other purposes).

Still, we have wanted to respond to the concern expressed above that there is significant likelihood that $\Delta T_{2 X}$ lies above the maximum value we adopt of $4{ }^{\circ} \mathrm{C}$, and have therefore also performed model runs for values of 5 and $6^{\circ} \mathrm{C}$. Under these climate sensitivities, we find that a $2{ }^{\circ} \mathrm{C}$ climate stabilisation goal requires extraordinarily steep emission reductions in the very short term. By 2020, carbon emissions should be reduced by about $30 \%$ in the $5{ }^{\circ} \mathrm{C}$ sensitivity scenario, and by about $70 \%$ in the $6{ }^{\circ} \mathrm{C}$ scenario, both with respect to 2000 emission levels. The $6{ }^{\circ} \mathrm{C}$ sensitivity run requires even close to a $50 \%$ emission reduction by as early as 2010 and emissions close to zero by the middle of the century. On the one hand, DEMETER is not really developed for calculating such emission reduction schemes, given the inertia that have purposefully been built into the model, e.g. through the simulation of an energy system vintage structure. On the other hand, we think that so radical reductions in global emissions are practically unrealistic. We have therefore not included in Fig. 1 the additional scenarios corresponding to the two high sensitivity values. ${ }^{14}$ In addition to our analysis allowing the inspection of a large range of different climate sensitivity values, our method is novel because our

\footnotetext{
${ }^{14} \mathrm{An}$ appendix to this paper, including figures, which describes more extensively the modelling results under the 5 and $6{ }^{\circ} \mathrm{C}$ climate sensitivities, is available from the authors.
} 
Table 1

Sensitivity analysis for emissions, energy savings share in emission reductions, and carbon-free share in energy supply, under different climate sensitivities and climate constraints

\begin{tabular}{|c|c|c|c|c|c|c|}
\hline & $\begin{array}{l}\text { Lower } \\
\text { value }\end{array}$ & $\begin{array}{l}\text { Basis } \\
\text { value }\end{array}$ & $\begin{array}{l}\text { Upper } \\
\text { value }\end{array}$ & $\begin{array}{l}\text { Emissions in } \\
2020(\mathrm{GtC} / \mathrm{yr})\end{array}$ & $\begin{array}{l}\text { Energy savings/ } \\
\text { emission reduction } \\
\text { in } 2020(\%)\end{array}$ & $\begin{array}{l}\text { Non-fossil share } \\
\text { in } 2020(\%)\end{array}$ \\
\hline Basis (with $2 \mathrm{C}$ climate constraint) & & & & 7.8 & 52 & 12 \\
\hline Climate sensitivity (C/doubling) & 4 & 3 & 2 & $(5.8,8.3)$ & $(48,49)^{\mathrm{a}}$ & $(9,27)^{\mathrm{a}}$ \\
\hline $\mathrm{CO}_{2}$ concentration constraint (ppmv) & 450 & & 550 & $(7.4,8.3)$ & $(49, \mathbf{5 3})^{\mathrm{a}}$ & $(9,14)^{\mathrm{a}}$ \\
\hline Overall range & & & & $(5.8, \mathbf{8 . 3})$ & $(48,53)$ & $(9,27)$ \\
\hline
\end{tabular}

N.B. The largest extremities reached are in bold and are indicated in the last row as 'overall range'.

${ }^{a}$ Denotes intervals where the lower bound of the sensitivity result is associated with the upper value of the corresponding parameter.

findings are obtained with DEMETER, which uniquely combines features of top-down modelling with those of bottom-up simulations, and includes endogenous technical change through learning curves.

Our sensitivity analysis regarding the climate sensitivity parameter can also be interpreted as one regarding the temperature constraint used in our policy scenarios, with temperature increase targets of $1.5,2$ and $3{ }^{\circ} \mathrm{C}$, respectively. To put it more precisely, varying the climate sensitivity from a central value of $3{ }^{\circ} \mathrm{C} /$ doubling down to a lower value of $2{ }^{\circ} \mathrm{C} /$ doubling, under a $2{ }^{\circ} \mathrm{C}$ stabilisation constraint, is equivalent to keeping the climate sensitivity at $3{ }^{\circ} \mathrm{C}$ /doubling, but increasing the temperature target from 2 to $3{ }^{\circ} \mathrm{C}$. Inversely, varying the climate sensitivity from a central value of $3{ }^{\circ} \mathrm{C} /$ doubling up to a value of $4{ }^{\circ} \mathrm{C} /$ doubling, under a $2{ }^{\circ} \mathrm{C}$ stabilisation constraint, is equivalent to keeping the climate sensitivity at $3{ }^{\circ} \mathrm{C} /$ doubling, but decreasing the temperature target from 2 to $1.5^{\circ} \mathrm{C}$.

We have generated two additional policy scenarios, as an extra check regarding the sensitivity of our results to different climate change targets. We have changed our $2{ }^{\circ} \mathrm{C}$ constraint into an atmospheric $\mathrm{CO}_{2}$ concentration constraint, of 450 and $550 \mathrm{ppmv}\left(\mathrm{CO}_{2}\right)$, respectively, the results of which are shown in Fig. 1(A). As can be seen, for the long-term, a constraint on the atmospheric $\mathrm{CO}_{2}$ concentration of 450 ppmv is slightly more flexible than a $2{ }^{\circ} \mathrm{C}$ constraint with a $3{ }^{\circ} \mathrm{C}$ /doubling climate sensitivity. But for (more than) the first half of the century, it is a more stringent constraint. The $550 \mathrm{ppmv} \mathrm{CO}_{2}$ concentration scenario resembles the $2{ }^{\circ} \mathrm{C}$ constraint scenario with $2{ }^{\circ} \mathrm{C} /$ doubling climate sensitivity.

How do our assumptions regarding the relationship between $\mathrm{CO}_{2}$ emissions, the atmospheric $\mathrm{CO}_{2}$ concentration, and the global average surface temperature determine our results? To answer this question, we replaced the 1-box representation as used in the early DICE model [11] by a more detailed 3-layer climate change module as employed in the later RICE model [45]. The latter involves a distinction between three physical entities: the atmosphere, the biosphere (upper ocean), and the lower ocean. Fig. 1(B) shows the 'optimal' $\mathrm{CO}_{2}$ emissions equivalent to those of Fig. 1(A), but obtained by using the 3-layer instead of the 1-box climate module; it demonstrates that the emission paths remain essentially the same when including another climate module. Qualitatively we find the same emission patterns, while quantitatively replacing the 1-box climate module by the 3-layer model implies a slightly tighter emission reduction scheme (and hence a somewhat enhanced transition to the use of non-carbon energy). ${ }^{15}$

Table 1 displays the variability of emissions, the share of energy savings in total emission reductions, and the share of carbon-free energy sources in total energy supply, in 2020, under three different climate sensitivities and two different concentration constraints. As can be seen, the emission reduction effort (first results-column) strongly depends on the assumed climate sensitivity, and also varies over the carbon concentration constraint employed. The extent to which energy savings are used as instrument to reach the climate objective is little dependent on the value of either the sensitivity or constraint. In formal terms, the

\footnotetext{
${ }^{15} \mathrm{We}$ have done this climate module test also with regard to the analysis presented below. Also there, it proves, adopting a different climate model affects only marginally our findings. In fact, our results appear to move a little more towards those obtained by Caldeira et al. [3].
} 
Table 2

Emissions and carbon-free share in total energy supply, in 2020, under different climate sensitivities

\begin{tabular}{|c|c|c|c|c|}
\hline & & & \multicolumn{2}{|c|}{ Climate sensitivity } \\
\hline & & & 2 & 4 \\
\hline Emissions in $2020(\mathrm{GtC} / \mathrm{yr})$ & & $\begin{array}{l}\text { This study } \\
\text { Caldeira et al. [3] }\end{array}$ & $\begin{array}{l}8.3 \\
8.0\end{array}$ & $\begin{array}{l}5.8 \\
4.8\end{array}$ \\
\hline Non-fossil share in $2020(\%)$ & $\begin{array}{l}\text { (Energy) } \\
\text { (Electricity) }\end{array}$ & $\begin{array}{l}\text { This study } \\
\text { Caldeira et al. [3] }\end{array}$ & $\begin{array}{c}9 \\
34\end{array}$ & $\begin{array}{l}27 \\
60\end{array}$ \\
\hline
\end{tabular}

N.B. The quoted Caldeira et al. [3] data are obtained through inspection of their Figs. 1 and 2.

savings vs. total emission reductions share can be expressed as

$$
\frac{\left(E_{t}^{B A U}-E_{t}^{2 C}\right)}{E_{t}^{B A U}} / \frac{\left(E m_{t}^{B A U}-E m_{t}^{2 C}\right)}{E m_{t}^{B A U}},
$$

where $E_{t}^{B A U}$ is the energy level in the BAU scenario, $E_{t}^{2 C}$ the energy level in the $2{ }^{\circ} \mathrm{C}$ climate-constrained scenario, $E m_{t}^{B A U}$ are the emissions in the BAU scenario, and $E m_{t}^{2 C}$ the emissions in the $2{ }^{\circ} \mathrm{C}$ scenario (all dependent on time $t$ ). By 2020, about half of the emission reductions are attained through savings.

The non-fossil share of energy supply, in 2020-hence the extent to which a transition towards non-fossil fuels is realised by then - displays a significant dependence on the parameter values used, especially in case of the climate sensitivity parameter.

How do these results compare with those found in the literature? Table 2 juxtaposes our findings, for two (rather extreme) climate sensitivity values, next to the ones presented in [3], and indicates that, apart from a number of similarities, a few seemingly important differences exist. With a $2{ }^{\circ} \mathrm{C} /$ doubling climate sensitivity, 2020 emissions in our study are found to be roughly the same as those in [3]; increasing this sensitivity to $4{ }^{\circ} \mathrm{C}$ /doubling induces considerable decreases in emissions, of $30 \%$ and $39 \%$ in the two cases, respectively. As for the carbon-free share in total energy supply, in 2020, we find that its value triples, from $9 \%$ to $27 \%$, when changing the climate sensitivity from 2 to $4{ }^{\circ} \mathrm{C}$ /doubling. Caldeira et al. [3] find that this value almost doubles, from $34 \%$ to $60 \%$. For the non-fossil energy share, their results differ less from ours than may seem from quick examination: we express non-fossil shares with respect to total energy supply, while they do so in comparison to total electric power generation. This explains that the numbers displayed differ by a factor of about 4 ( 9 compared to 34 , in the $2{ }^{\circ} \mathrm{C} /$ doubling case) to 2 ( 27 compared to 60 , in the $4{ }^{\circ} \mathrm{C} /$ doubling case). The difference in results between these two factors, 4 and 2, respectively, can be explained as well. Increasing the share of power production in energy supply proves the most efficient way to increase the share of (mostly electric) non-fossil energy in total supply. With a high $\left(4^{\circ} \mathrm{C} /\right.$ doubling $)$ climate sensitivity, reaching the $2{ }^{\circ} \mathrm{C}$ climate constraint is much more ambitious than in the $2^{\circ} \mathrm{C}$ /doubling case, that is, much more carbon-free energy needs to be employed (in a rather short time). Hence, in the $4{ }^{\circ} \mathrm{C} /$ doubling case the electricity-to-totalenergy ratio is likely to be significantly higher than in the $2{ }^{\circ} \mathrm{C}$ /doubling case, explaining why the numbers 27 and 60 lie closer in each other's vicinity (that is, differ by 'only' about a factor of two) than 9 and 34 (off by a factor of almost 4). Overall, the results prove thus consistent.

We observe, with Caldeira et al. [3], that even under central assumptions for the climate constraint and sensitivity, a massive transition towards non-fossil energy is called for. By the end of the century, between $75 \%$ and $100 \%$ of total power demand will need to be provided by non- $\mathrm{CO}_{2}$ releasing energy sources [3], or, in between $80 \%$ and $90 \%$ of total energy supply (our analysis).

In this article we go a few steps further and exploit the advantages of using a top-down model like DEMETER: we have calculated the relative importance of energy savings versus the transition from $F$ towards non- $F$ energy sources for reaching the climate stabilisation objective. In [19], we reported our findings regarding the share of emission reductions, relative to the BAU benchmark, reached through energy savings measures (the first policy option, as also displayed in the second results-column of Table 1). The remainder of 


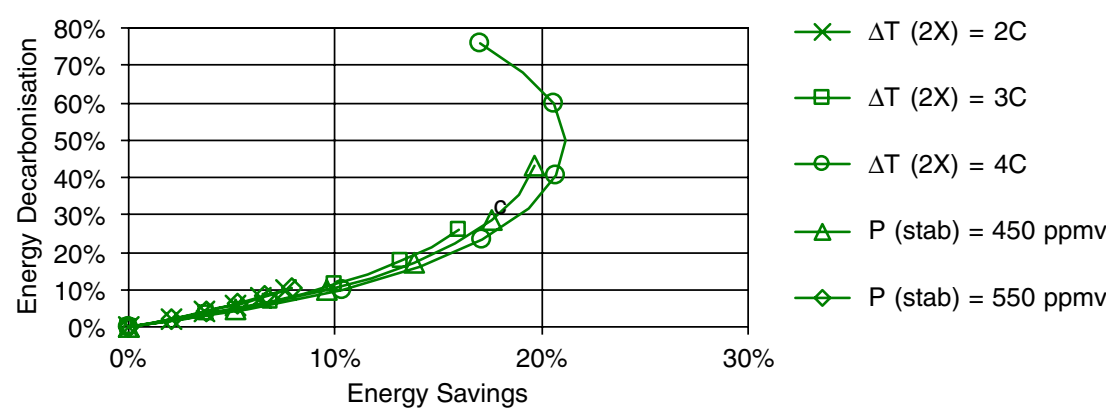

Fig. 2. Relative importance of energy savings and energy decarbonisation in total emissions reduction under different climate change parameters until 2050.

the emission reductions, we concluded, is reached through the second policy option (a transition to non- $F$ energy sources). Let's here expand on the mechanisms through which emission reductions take place. In Fig. 2, we present the trade-off between energy savings and the decarbonisation of energy supply. That is, for reaching the climate stabilisation target, the model chooses between decreasing the energy intensity of total output, on the horizontal axis, versus decreasing the emissions per energy output by shifting energy supply to non-carbon energy sources, on the vertical axis. The figure presents the relative use of these two options for the period 2000-2050. The figure shows that the path is almost entirely independent of the climate change target or the climate sensitivity used, although the extent of progression along the path depends significantly on the stringency of the climate change target or the value of the climate sensitivity. The figure shows that energy savings constitute mainly an option for moderate and medium emission reductions. The first part of emission reductions is reached through both energy savings and energy decarbonisation, both in approximately equal shares, consistent with the reporting in Table 1 . When energy savings exceed the level of $20 \%$, it becomes an expensive option, in relative terms, and the development of the non-carbon energy source becomes more favourable. The curve thus bends backwards. For a substantial cut in emissions, the policy option of energy savings is then used to only a limited extent at most. The explanation is that, when the non- $F$ energy source has reached a substantial share in total energy supply, it has become sufficiently competitive to take over the role of the $F$ energy source as the main contributor to total energy supply. ${ }^{16}$ Also for this figure we have generated model runs with climate sensitivities of 5 and $6{ }^{\circ} \mathrm{C}$. As the corresponding decarbonisation rapidity and emission reduction requirements are too significant and too soon, we have not included them in this graph. $^{17}$

The similarity of the curves in Fig. 2 for different climate sensitivities leads us to question whether the relative importance of energy savings vs. energy decarbonisation in total emissions reduction perhaps also shows a certain independence from other parameters in our model. Let's therefore turn from the main thrust of our analysis, and see whether we can confirm or moderate the uniqueness of our results of Fig. 2: apart from showing the savings vs. decarbonisation dependence (or rather independence) on the value adopted for the climate change sensitivity, we present a similar figure for the central climate change parameters, but now with different economic or technology diffusion parameters. Fig. 3 depicts four additional $\left(2{ }^{\circ} \mathrm{C}\right)$ scenarios in which the learning rate (LR) and energy substitutability $(\sigma)$ are changed to other-than-central values, to demonstrate the impact of certain important parameter modifications. It can be seen from Fig. 3 that if the non- $F$ energy source has sufficient potential to replace the fossil-fuelled one, that is, if the learning rate is $30 \%$ or the substitution elasticity $\sigma$ has value 4 , the transition to the non- $F$ energy source is the main mechanism for emissions reduction, even in early periods. These cases correspond to the curves on the left-hand side of the graph. Conversely, when the non- $F$ energy source possesses no good capacity to replace fossil fuels (curves on the right-hand side of the graph), that is, when we assume a low learning rate, $\mathrm{LR}=10 \%$, or a low

\footnotetext{
${ }^{16}$ The value of the relative importance of energy savings in the total amount of emissions reduction may fall below zero in the long run (that is, by end of the century): a very successful transition to non- $F$ energy permits an expansion of total future energy use.

${ }^{17}$ They are given in the aforementioned appendix dedicated to these high climate sensitivity values.
} 


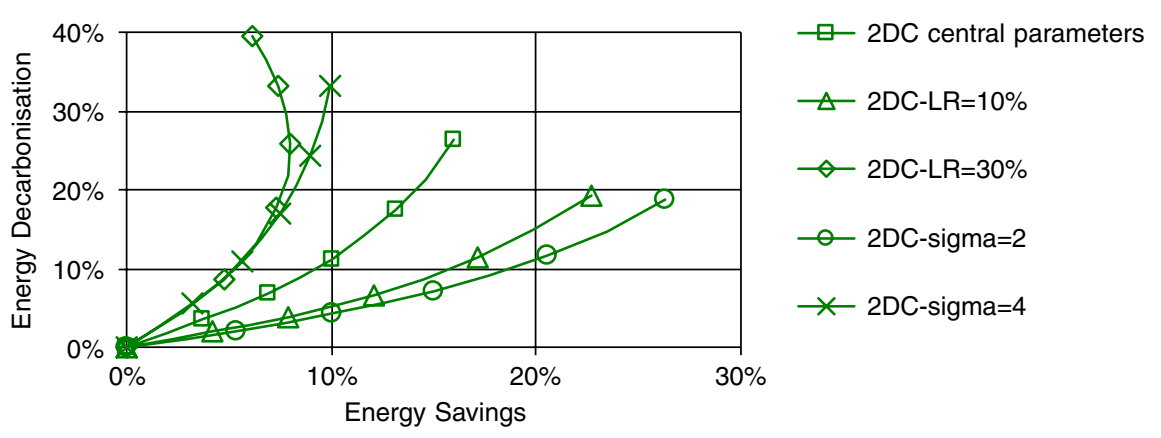

Fig. 3. Relative importance of energy savings and energy decarbonisation in total emissions reduction under different economic parameters until 2050 .

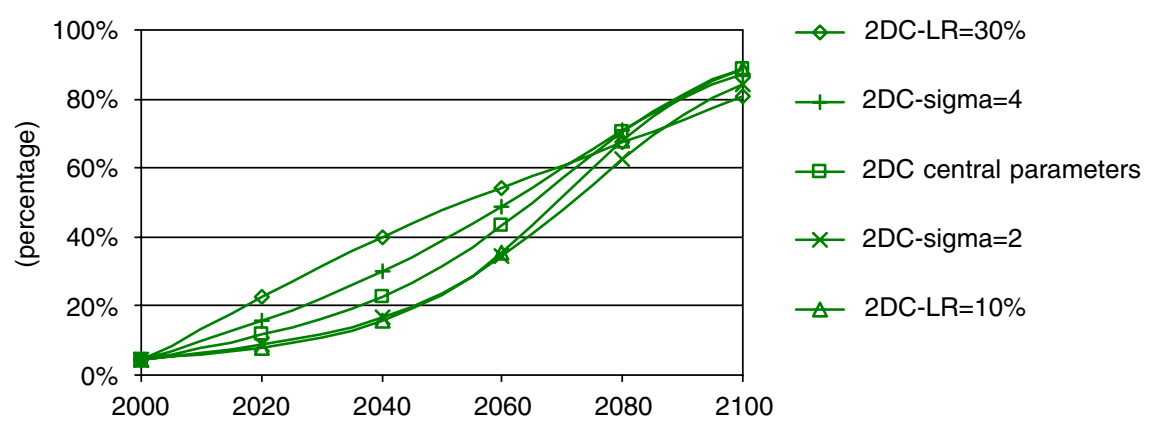

Fig. 4. Fraction of energy supply produced by the carbon-free technology.

substitution elasticity, $\sigma=2$, energy savings remain one of the important windows for emissions reduction in both the short and medium term (i.e., until about 2050).

Nonetheless, in the long-term (that is, during the 2nd half of the 21st century, not shown in Fig. 3), the transition to the non-carbon energy source appears to remain the dominant strategy. To complement Fig. 3 and to depict the role of $N$ over time in DEMETER, Fig. 4 shows the share of the non- $F$ energy source in total energy supply for $2{ }^{\circ} \mathrm{C}$ temperature-constrained scenarios. While in the short term the transition to (and thus the share in total supply of) non-fossil energy remains sensitive to economic parameter values, in the longer run the transition becomes the predominant method to reach climate objectives, and becomes almost insensitive to choices for the values of parameters LR and $\sigma$. For the central parameter choice, the non-fossil share increases by nearly $1 \%$ per year, to a share of about $95 \%$ in 2100 . This finding portrays a substantial acceleration in the transition of the energy system to non- $F$ energy sources in comparison to the BAU reference scenario (not plotted in the figure). In the BAU scenario, under central parameter values, the share of the non- $F$ energy source increases from $4 \%$ in 2000 to $33 \%$ in 2100 .

After this intermezzo, we end by turning to the main subject of this paper, the effect of assuming different climate sensitivities on long-term temperature-constrained energy supply scenarios, in particular the impact on the timing of required emission reductions. In particular, we want to confirm the acclaimed necessity of realising early carbon emission reductions. For this purpose, we need a more precise meaning of emissions abatement timing that constitutes a common measure of timing applicable to scenarios defined by different parameter values and/or climate constraints. We define the emissions reduction effort in period $t$ under a climate-constrained (e.g. $2{ }^{\circ} \mathrm{C}$ ) scenario as the amount of emissions reduced relative to the emissions level in the BAU scenario. The timing of abatement can be presented as the development over time of the emissions reduction effort, relative to this same effort in 2050 , formally calculated by

$$
\frac{\left(E m_{t}^{B A U}-E m_{t}^{2 C}\right)}{E m_{t}^{B A U}} / \frac{\left(E m_{2050}^{B A U}-E m_{2050}^{2 C}\right)}{E m_{2050}^{B A U}},
$$




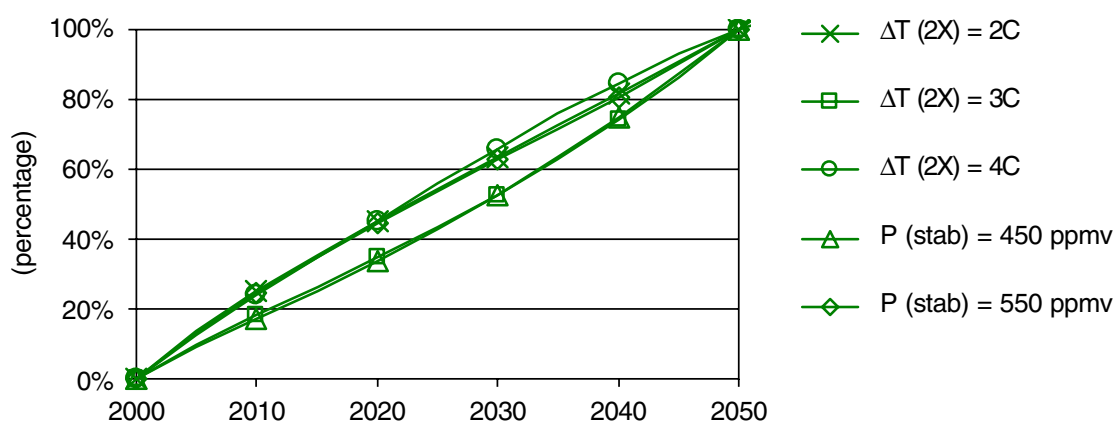

Fig. 5. Timing of emission reduction efforts, relative to BAU and 2050.

where $E m_{t}^{B A U}$ are emissions in the BAU scenario, and $E m_{t}^{2 C}$ are emissions in the $2{ }^{\circ} \mathrm{C}$ scenario (the subscripts $t$ and 2050 indicating the particular moments in time under consideration). The results are presented in Fig. 5 for scenarios with the three earlier different climate sensitivity values (with a $2{ }^{\circ} \mathrm{C}$ temperature constraint) and the two carbon concentration constraint values. The figure shows that the emissions reduction effort is almost linearly increasing in time, and is almost unaffected by either changes in the climate sensitivity assumed or the $\mathrm{CO}_{2}$ concentration constraint imposed. ${ }^{18}$ Given the way we define the emissions reduction indicator, it is not surprising we find a fan-like pattern: Eq. (5) implies that the 2000 and 2050 points are fixed to the lower left and upper right corners, respectively, for all values of the climate sensitivity and policy goal. It is a remarkable finding, however, that all five curves deviate so little from a linear intrapolation between these two corners, that is, that we observe such a 'narrow fan'. This is noteworthy, first, because the calculated emission paths vary widely among different climate sensitivities and targets, as we have seen in Fig. 1. Second, due to the vintage structure of DEMETER, emission intensities are fixed for old vintages. Thus, the linear path of the emissions reduction effort has to be reached through a substantial cut in the emission intensity of new vintages. Summarising, we observe that although the overall emissions reduction effort (obviously) depends strongly on both the climate sensitivity and objective, the timing of the effort is almost linear and independent of either this sensitivity or policy target.

\section{Conclusions}

In this paper we have, first of all, provided further evidence of the claim brought forward in one of our recent publications [19] that by playing around with the values of some of the parameters used in climate change models one loses significance in the findings derived from them. In particular, in the analysis presented in this paper we have done so regarding the climate sensitivity parameter. We have demonstrated that whether one assumes 2,3 or $4{ }^{\circ} \mathrm{C}$ temperature increase per doubling of the atmospheric $\mathrm{CO}_{2}$ concentration matters a lot for the calculated emission path during the 21 st century. Meanwhile, however, we have pointed out that irrespective of the climate sensitivity assumed, many results continue to hold. Regarding carbon emissions we have seen that substantial reductions are called for, under whatever climate sensitivity, and that, sooner or later, the emission path should be pushed downwards in order to reach climate change objectives. Indeed, the obligatory energy supply transformation that follows from our model continues to hold, even under large variations of the value of the sensitivity parameter: by the end of the century the vast majority of energy production should be non-fossil based. Mankind ought to fundamentally change the present energy system from largely fossil-based to non-fossil or at least non- $\mathrm{CO}_{2}$-emitting resources, independent of the value of the climate sensitivity, that is, whether at the low or high end of the canonical IPCC range, and surely when one

\footnotetext{
${ }^{18}$ Note that while linearity holds in the units as expressed by Eq. (5) (in \% reduction per annum), linearity may not hold if the timing of emission reductions were expressed differently. Note also that because we consider the emission reductions required when the climate sensitivity is 5 or $6{ }^{\circ} \mathrm{C}$ unrealistically rapid, we have not included the corresponding scenarios in Fig. 5 (they are given in the aforementioned appendix). Interestingly, the model runs generated with these sensitivity values show that in these cases (near-)linearity, even in Eq. (5) units, no longer holds.
} 
accounts for the increasing evidence that this parameter may well have a value higher than this range. We have also performed model runs with climate sensitivities above the IPCC range, at values of 5 and $6{ }^{\circ}$, to reflect the probability that $\Delta T_{2 X}$ may lie above the upper value of $4.5^{\circ} \mathrm{C}$. While at such high values of $\Delta T_{2 X}$ DEMETER operates at the confines of the parameter domain it was designed for, and produces decarbonisation profiles that we think fall beyond the fringes of what is practically achievable in terms of global $\mathrm{CO}_{2}$ emission reductions the coming decade, our central finding continues to hold, and proves to be even more pronounced: the need to fundamentally transit our current energy system away from $\mathrm{CO}_{2}$-emitting sources is urgent.

As explained, DEMETER models physical and economic inertia through the combined simulation of several energy system features (among which, notably, a vintage structure, CES aggregation and learning curves). With the present analysis, we find that it basically takes a century in order for the energy system to be transformed from fossil to non-carbon based. In the past, it also typically took such time frames for energy technologies to develop from nascence to full maturity and/or primordial significance. For example, the transition during the 19th century from a traditional biomass combustion based energy infrastructure to one in which coal was the main energy resource spanned about 100 years [26]. Hence, our combined simulation of the mentioned energy system features results in realistic annual technology expansion rates, similar to the ones that have been observed historically.

We have seen that the emission reductions that ought to be reached in 2020 are strongly dependent on the value of the climate sensitivity, as is the non-fossil share in total energy supply realised in that year. The extent to which energy savings are used to meet reasonable climate requirements, however, depends little on this sensitivity: by 2020 around half of emission reductions should be attained through savings. We have paid particular attention to compare our results with those of Caldeira et al. [3]. A number of numerical differences appeared to exist between their and our analysis results, but most of these were more or less explainable, or merely resulted from the difference in nature between the respective models used. Most importantly, we have confirmed one of their main conclusions. As stated by the IPCC, the temperature increase resulting from a doubling in $\mathrm{CO}_{2}$ concentration is probably known only to about a factor of three. This uncertainty propagates from climate stabilisation objectives, to allowable carbon concentrations and emissions, and finally to nonfossil-based energy production. Uncertainties in the current scientific understanding of climate sensitivity introduce the largest possible uncertainties in allowable $\mathrm{CO}_{2}$ emission paths [3], as we confirm in Fig. 1. It is thus not surprising that these uncertainties exceed those induced by the uncertainty with which we understand the complexity of the carbon cycle [3]. But, and this is the central thrust of our research, even if climate sensitivity is at the low end of the currently accepted range (or other modelling parameters are chosen such so as to obtain the most optimistic climate results possible), our model and temperature constraint dictate that by the end of the century over three-quarters of mankind's total energy supply will need to come from sources that do not emit $\mathrm{CO}_{2}$ in the terrestrial atmosphere.

The results reported here have been obtained with the integrated assessment climate model DEMETER, which includes two energy sources and learning-by-doing for both of these (fossil and non-fossil) energy sources. This top-down model allows us to study the two main options for achieving substantial reductions in $\mathrm{CO}_{2}$ emissions. The first is the energy savings option, in which the substitution of capital and labour for energy is allowed for. The second is the energy transformation option, in which emission reductions can be achieved through a transition from a carbon energy technology towards a carbon-free technology. The first option turns out to be of most importance in the short run, whereas the second option is needed to reach substantial emission reductions in the long run. The finding that the transformation from carbon to non-carbon energy technologies starts to play a major role only after a few decades should not create the impression that little action is called for today. On the contrary, the emission paths determined by DEMETER clearly show that in order to stabilize climate change at an increase of the atmospheric temperature of $2{ }^{\circ} \mathrm{C}$, substantial emission reductions are also called for in the short and medium term.

To complement and further support our findings, this analysis has also shown that the main results regarding the required global energy transformation are robust against changes in the values of even the most sensitive economic and technological parameters (see Figs. 3 and 4, complementing [19]). The numerical results on the role of energy savings and the carbon-free technology appear most sensitive to the learning rate of the non- $F$ energy source, on the one hand, and the substitution possibilities between this energy source 
and the fossil-fuelled technology, on the other hand. The sensitivity of our results to the learning rate is understandable, since this rate determines the intensity of the mechanism that promotes accelerated price decreases. The learning rate contributes to determining the speed with which the transition towards a largescale use of non- $F$ energy - and thus the reduction of carbon emissions - takes place. It is not surprising either that our findings are sensitive to the value of the substitution elasticity $\sigma$, describing the substitution potential between the two energy sources. Increasing the value of this elasticity increases the potential of a transition policy and reduces the role played by energy savings. The levels of carbon taxes and subsidies for the non- $F$ energy source, required to reach the temperature change stabilisation objective, were reported on in earlier publications (see, e.g., [20]): they remain relatively independent of the value of these two parameters. We also undertook analysing the policymaking-relevant subject of emissions reduction timing, for which we defined a common emission-abatement timing measure. We conclude that although the overall emission reduction effort depends strongly on the climate sensitivity assumed, the timing of the effort is almost independent of this sensitivity.

With our findings, we have further backed the acclaimed importance of non-carbon energy resources gradually taking over, during the 21 st century, currently cheaply available conventional fossil fuels. Not only for the sciences occupied with solving the global warming problem, but also for those engaged in apprehending how to establish sustainable development at large (including, for example, the question how to preserve global biodiversity; see [41]), providing an understanding of how to materialise such a transition is fundamental. This paper demonstrates - like a growing body of other studies - the need for mankind to make a substantial transition, over the decades to come, from fossil to non-fossil energy use. While this conclusion is robust across many different analyses and models, many other of our results are of course - as with many (economic) models - driven by the initial assumptions made. For example, we do not simulate more flexibility to realise carbon emission reductions than through either energy savings or an energy transition, thereby restricting ourselves to mainly these two global warming mitigation channels. Also, and admittedly, our assumptions on learning rates and energy substitution elasticities allow for a radical energy technology shift to take place. Indeed, if cheap carbon capture and storage or dramatic improvements in energy efficiency could be realised (and correspondingly modelled in DEMETER), then the need for non-fossil non- $\mathrm{CO}_{2}$ releasing energy technologies would most likely be significantly less than suggested in this paper. These subjects are among our future research plans.

\section{Acknowledgements}

The work that lead to this publication has been performed under the EU-funded NEMESIS/ETC project, known at the European Commission under contract No. ENG2-CT-2001-00538. This EU grant is greatly acknowledged by both authors. Bob van der Zwaan acknowledges Marty Hoffert for sharing his views on this paper's subject matter, as well as the comments during the presentation of an earlier version of this article from participants of the 2004 International Energy Workshop, held in Paris on 22-24 June 2004. The writing of this article has been stimulated by the thoughtful feedback from several respected colleagues, and by numerous presentations on the subject of climate uncertainty given at the MIT Global Change Forum XXI, Climate Uncertainty, Long-term Goals, and Current Mitigation Effort, Cambridge MA, 8-10 October 2003. The detailed and thoughtful suggestions from 2 anonymous reviewers (and 3 previous referees who reviewed an earlier version) have significantly increased the quality of this paper and have embedded it better in the latest literature on the topic of climate sensitivity uncertainty. The authors are responsible for all remaining errors.

\section{References}

[1] IPCC. In: Houghton JT, et al., editors. Climate change 1995: the science of climate change. Cambridge, UK: Cambridge University Press; 1996.

[2] IPCC. Climate Change 2001: In: Houghton JT, et al., editors. The scientific basis. Cubasch U, et al. contribution of working group I to the third assessment report of the intergovernmental panel on climate change. Cambridge, UK: Cambridge University Press; 2001. 
[3] Caldeira K, Jain AK, Hoffert MI. Climate sensitivity uncertainty and the need for energy without $\mathrm{CO}_{2}$ emission. Science 2003;299(5615):2052-4.

[4] Lempert RJ, Schlesinger ME, Bankes SC, Andronova NG. The impacts of climate variability on near-term policy choices and the value of information. Climatic Change 2000;45:129-61.

[5] Ambrosi PH, Hourcade J-C, Hallegatte S, Lecocq F, Dumas P, Ha-Duong M. Optimal control models and elicitation of attitudes towards climate damages. Environ Model Assess 2003;8:133-47.

[6] Nordhaus WD, Popp D. What is the value of scientific knowledge? An application to global warming using the PRICE model. Energy J 1997;18(1):1-45.

[7] Keller K, Bolker BM, Bradford DF. Uncertain climate thresholds and optimal economic growth. J Environ Econ Manage 2004;48:723-41.

[8] MIT Global Change Forum XXI. Climate uncertainty, long-term goals, and current mitigation effort. Cambridge, MA; 8-10 October 2003.

[9] Berry RS, Heal G, Salomon P. On a relation between economic and thermodynamic optima. Resource Energy 1978;1:125-37.

[10] Wigley TML, Richels R, Edmonds JA. Economic and environmental choices in the stabilization of atmospheric $\mathrm{CO}_{2}$ concentrations. Nature 1996;379(6562):240-3.

[11] Nordhaus WD. Managing the global commons. Cambridge, MA: MIT Press; 1994.

[12] Manne AS, Mendelsohn R, Richels R. Merge, a model for evaluating regional and global effects of GHG reduction policies. Energy Policy 1995;23:17-34.

[13] Nordhaus WD, Yang Z. A regional dynamic general equilibrium model of alternative climate-change strategies. Am Econ Rev 1996;86:741-65.

[14] Peck SC, Teisberg TJ. CETA, a model for carbon emissions trajectory assessment. Energy J 1992;13:55-77.

[15] Tol RSJ. Spatial and temporal efficiency, climate policy, applications of FUND. Environ Resource Econ 1999;14:33-49.

[16] Gerlagh R, van der Zwaan BCC, Hofkes MW, Klaassen G. Impacts of $\mathrm{CO}_{2}$-taxes in an economy with niche markets and learning-bydoing. Environ Resource Econ 2004;28:367-94.

[17] Messner S. Endogenized technological learning, an energy systems model. Laxenburg, Austria: WP-95-114, IIASA; 1995.

[18] Gerlagh R, van der Zwaan BCC. Gross world product and consumption in a global warming model with endogenous technological change. Resource Energy Econ 2003;25:35-57.

[19] Gerlagh R, van der Zwaan BCC. A sensitivity analysis of timing and costs of greenhouse gas emission reductions under learning effects and niche markets. Climatic Change 2004;65:39-71.

[20] van der Zwaan BCC, Gerlagh R, Klaassen G, Schrattenholzer L. Endogenous technological change in climate change modelling. Energy Econ 2002;24(1).

[21] Carraro C, Gerlagh R, van der Zwaan BCC. Endogenous technical change in environmental macroeconomics. Resource Energy Econ 2003;25:1-10.

[22] Chakravorty U, Roumasset J, Tse K. Endogenous substitution among energy resources and global warming. J Polit Econ 1997;105:1201-34.

[23] Goulder LH, Schneider SH. Induced technological change and the attractiveness of $\mathrm{CO}_{2}$ abatement policies. Resource Energy Econ 1999;21:211-53.

[24] Ha-Duong M, Grubb MJ, Hourcade J-C. Influence of socioeconomic inertia and uncertainty on optimal $\mathrm{CO}_{2}$-emission abatement Nature 1997;390(6657):270-3.

[25] Schneider SH, Azar C. Are uncertainties in climate and energy systems a justification for stronger near-term mitigation policies? Pew Center on Global Climate Change, www.pewclimate.org/events, workshop paper, 2001.

[26] Nakicenovic N, Grübler A, McDonald A, editors. Global energy perspectives. Cambridge, UK: IIASA-WEC, Cambridge University Press; 1998.

[27] World Bank. 1999 World development indicators. Washington, DC, USA; 1999.

[28] IPCC. In: Watson RT, editor. Land use, land-use change, and forestry. A special report of the IPCC. Cambridge, UK: Cambridge University Press; 2000.

[29] IEA/OECD. Key world energy statistics. Paris: International Energy Agency, OECD; 1999.

[30] IEA/OECD. Experience curves for energy technology policy. Paris: International Energy Agency, OECD; 2000.

[31] McDonald A, Schrattenholzer L. Learning rates for energy technologies. Energy Policy 2001;29(4):255-61.

[32] Kerr RA. Three degrees of consensus. Science 2004;305(5686):932-4.

[33] Tol RSJ, de Vos AD. A Bayesian statistical analysis of the enhanced greenhouse effect. Climatic Change 1998;38:87-112.

[34] Andronova NG, Schlesinger ME. Objective estimation of the probability density function for climate sensitivity. J Geophys Res 2001;106:22,605-12.

[35] Forest CE, Stone PH, Sokolov AP, Allen MR, Webster MD. Quantifying uncertainties in climate system properties with the use of recent climate observations. Science 2002;295(5553):113-7.

[36] Gregory JM, Stouffer RJ, Raper SCB, Stott PA, Rayner NA. An observationally based estimate of the climate sensitivity. J Climate 2002;15:3117-21.

[37] Knutti R, Stocker TF, Joos F, Plattner G-K. Probabilistic climate change projections using neural networks. Climate Dyn $2003 ; 21: 257-72$.

[38] Meehl GA, Washington WM, Collins WD, Arblaster JM, Hu A, Buja LE, et al. How much more global warming and sea level rise? Science 2005;307(5716):1769-72.

[39] Wigley TML. The climate change commitment. Science 2005;307(5716):1766-9. 
[40] Schneider SH, editor. Editorial. Climatic Change 2002:52.

[41] van der Zwaan BCC, Petersen AC, editors. Sharing the planet: population — consumption — species. Delft: Eburon; 2003.

[42] Yohe G, Andronova N, Schlesinger M. To hedge or not against an uncertain climate future? Science 2004;306(5695):416-7.

[43] Andronova NG, Schlesinger ME. Causes of global temperature changes during the 19th and 20th centuries. Geophys Res Lett 2000;27:2137-40.

[44] Kerr RA. Reducing uncertainties of global warming. Science 2002;295(5552):29-31.

[45] Nordhaus WD, Boyer J. Warming the world: economic models of global warming. Cambridge, MA: MIT Press; 2000. 